\title{
Cross-species pharmacological characterization of the allylglycine seizure model in mice and larval zebrafish
}

\author{
Karine Leclercq ${ }^{\mathrm{a}, 1}$, Tatiana Afrikanova ${ }^{\mathrm{b}, 1}$, Melanie Langlois ${ }^{\mathrm{c}}$, An De Prins ${ }^{\mathrm{d}}$, Olivia E. Buenafe ${ }^{\mathrm{b}}$, Chiara C. Rospo ${ }^{\mathrm{a}}$, \\ Ann Van Eeckhaut ${ }^{c}$, Peter A.M. de Witte ${ }^{\mathrm{b}}$, Alexander D. Crawford ${ }^{\mathrm{b}, \mathrm{c}}$, Ilse Smolders ${ }^{\mathrm{d}}$,

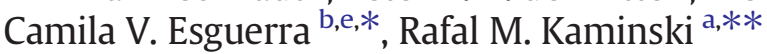 \\ a Neuroscience TA, UCB Biopharma, Braine-l'Alleud, Belgium \\ b Laboratory for Molecular Biodiscovery, Department of Pharmaceutical and Pharmacological Sciences, University of Leuven, Leuven, Belgium \\ c Luxembourg Center for Systems Biomedicine, University of Luxembourg, Esch-sur-Alzette, Luxembourg \\ d Center for Neurosciences, C4N, Faculty of Medicine and Pharmacy, Vrije Universiteit Brussel, Brussels, Belgium \\ e Chemical Neuroscience Group, Biotechnology Centre of Oslo, University of Oslo, Oslo, Norway
}

\section{A R T I C L E I N F O}

Article history:

Received 2 December 2014

Revised 16 March 2015

Accepted 17 March 2015

Available online 3 April 2015

\section{Keywords:}

Zebrafish

Treatment resistance

Seizures

Epilepsy

Allylglycine

Antiepileptic drugs

\begin{abstract}
A B S T R A C T
Treatment-resistant seizures affect about a third of patients suffering from epilepsy. To fulfill the need for new medications targeting treatment-resistant seizures, a number of rodent models offer the opportunity to assess a variety of potential treatment approaches. The use of such models, however, has proven to be timeconsuming and labor-intensive. In this study, we performed pharmacological characterization of the allylglycine (AG) seizure model, a simple in vivo model for which we demonstrated a high level of treatment resistance. (D,L)Allylglycine inhibits glutamic acid decarboxylase (GAD) - the key enzyme in $\gamma$-aminobutyric acid (GABA) biosynthesis - leading to GABA depletion, seizures, and neuronal damage. We performed a side-by-side comparison of mouse and zebrafish acute AG treatments including biochemical, electrographic, and behavioral assessments. Interestingly, seizure progression rate and GABA depletion kinetics were comparable in both species. Five mechanistically diverse antiepileptic drugs (AEDs) were used. Three out of the five AEDs (levetiracetam, phenytoin, and topiramate) showed only a limited protective effect (mainly mortality delay) at doses close to the $\mathrm{TD}_{50}$ (dose inducing motor impairment in 50\% of animals) in mice. The two remaining AEDs (diazepam and sodium valproate) displayed protective activity against AG-induced seizures. Experiments performed in zebrafish larvae revealed behavioral AED activity profiles highly analogous to those obtained in mice. Having demonstrated crossspecies similarities and limited efficacy of tested AEDs, we propose the use of AG in zebrafish as a convenient and high-throughput model of treatment-resistant seizures.
\end{abstract}

(c) 2015 Elsevier Inc. All rights reserved.

\section{Introduction}

Therapy resistance represents a major issue in the management of epilepsy. Diverse potential mechanistic causes have been proposed [1-4], and new experimental approaches have been established in order to discover therapies providing better efficacy $[5,6]$. Nevertheless, a clear medical need remains in order to achieve complete seizure

\footnotetext{
* Correspondence to: C. V. Esguerra, Chemical Neuroscience Group, Biotechnology Centre of Oslo, University of Oslo, Oslo Innovation Centre (Forskningsparken), Gaustadalléen 21, 0349 Oslo, Norway. Tel.: + 47228 40534, + 4795040178 (mobile); fax: +4722840501 .

** Correspondence to: R. M. Kaminski, Neuroscience TA, UCB Biopharma sprl, Avenue de l'Industrie, R9, B-1420 Braine-l'Alleud, Belgium. Tel.: + 322386 6499; fax: + 322386 3339.

E-mail addresses: c.v.esguerra@biotek.uio.no (C.V. Esguerra), rafal.kaminski@ucb.com (R.M. Kaminski).

1 These authors contributed equally to this work.
}

control in a substantial population of patients with treatmentresistant epilepsy [7].

Treatment-resistant epilepsy is defined clinically as a failure of adequate trials of two tolerated, appropriately chosen and used antiepileptic drug schedules (whether as monotherapies or in combination) to achieve sustained seizure freedom. Such a resistance might be complete or partial as the patient experiences a reduction in either seizure frequency or intensity [4]. Similarly, treatment resistance in animal models of epilepsy is defined as the persistence of seizure activity that does not respond to monotherapy with at least two appropriately chosen antiepileptic drugs (AEDs). It must be recognized, however, that the differentiation between complete responsiveness and partial responsiveness may be difficult in animals and depends on seizure protection endpoints [8].

Preclinical AED discovery has evolved from acute classical seizure models (chemical and electrical) to more complex designs involving the induction of spontaneous recurrent seizures and chronic monitoring 
or the selection of subpopulations of treatment nonresponder animals [9]. These models have allowed for the identification of some factors (molecular and genetic) linked to drug resistance in epilepsy, but they have limited throughput and are still not commonly used for drug testing purposes. For example, phenytoin-resistant kindled rats [10] and, more recently, lamotrigine-resistant kindled rats [11] were well characterized as potential models for treatment resistance, but they required an invasive surgical approach and a laborious selection process. Therefore, a simpler in vivo model suitable for larger scale early-stage drug development screening is still needed.

The zebrafish is an increasingly accepted model organism to study neurological disorders because of its similarity to humans with regard to neurotransmitter systems and stress axis organization [12]. It combines easy handling and relatively high-throughput screening with the complexity of a whole vertebrate organism. Within the past decade, the usefulness of zebrafish in epilepsy research has been validated through studies involving pharmacologically induced acute seizure models [13-15] as well as zebrafish models of genetic epileptic syndromes (Angelman's [16], Lowe's [17], BNFC [18], EAST [19], and Dravet $[20,21])$. More recently, some of these zebrafish models have been applied in high-throughput epilepsy drug discovery (PTZ [22] and Dravet [20]).

The GABAergic system, one of the main inhibitory neurotransmitter pathways, has proven to be a valuable target for AEDs. However, the possible routes of enhancement or modulation include positive allosteric modulation of $G_{A B A_{A}}$ receptors (diazepam, DZP) as well as, for example, inhibition of GABA reuptake (tiagabine, TGB) [23], synthesis, or metabolism (valproate, VPA and vigabatrin) $[24,25]$.

Glutamate, in contrast, is part of the principal excitatory pathway that interacts with both ionotropic receptors which open cationpermeable channels and G-protein-coupled metabotropic receptors $[26,27]$. It is well established that increased glutamate release can worsen or prolong seizure activity and plays a major role in the persistence of excitotoxicity [28-30]. Glutamate receptors are, therefore, also targeted by AEDs, e.g., topiramate (TPM) [31] and perampanel [32]. Furthermore, it has been suggested that convulsions may arise from either an impairment of GABAergic and/or excessive glutamatergic function [33-35]. Accordingly, although no consistent correlation was reported between ictal foci and reduced GABA levels in patients with drugrefractory seizures, glutamate decarboxylase (GAD, EC 4.1.1.15) activity was significantly decreased in the human cortex [36]. Interestingly, (D,L)-allylglycine (AG, 2-amino-4-pentenoic acid) interferes with the synthesis of GABA via a mixed-mechanism inhibition of GAD, leading to decreased GABA levels [37] and increased glutamine concentrations in the brain $[38,39]$, with glutamate levels remaining unchanged in these studies. As a result, the ratio between inhibitory and excitatory neurotransmitters was dramatically changed, which could lead to initiation of seizures after in vivo AG exposure. In vitro studies have shown $A G$ to be a rather weak GAD inhibitor, although regional variations in cerebral GAD activity following AG administration indicated possible differences in entry or metabolism of AG in the brain [40]. Oxidative deamination of AG resulted in the formation of its metabolite, 2-keto4-pentenoic acid, which was shown to be a more potent GAD inhibitor in mice [37].

Allylglycine has been reported to induce convulsions in rodents [37, 41] and goldfish [42] and to enhance epileptic responses triggered by photic stimulation in baboons [41]. However, only a few studies were performed to correlate in vivo convulsive behavior with cerebral GABA and glutamate levels after AG injection [37-39]. Furthermore, only a few pharmacological studies in the context of AG-induced seizures have been reported so far. An indirect protective effect was described for clobazam as it reversed the AG-induced decrease of convulsive threshold in baboons with photosensitive epilepsy [43]. Phenobarbital and VPA elevated the electroconvulsive threshold decreased by $A G$ in rats [44]. Flunarizine and some AEDs of the first generation (PHT, clonazepam, and primidone) were reported to decrease seizure occurrence and to delay mortality in rats following intravenous administration of AG, but active doses were much higher than those inducing motor impairment in the rotarod test $[45,46]$. Further pharmacological characterization should, therefore, be performed to obtain a more detailed profile of treatment responsiveness or resistance in the AG model in mice. Finally, there are no reports of the potential use of AG as a model of seizures in zebrafish.

With regard to clinical relevance, AG-mediated GAD inhibition probably best mimics human neurological conditions that lead to inhibitory interneuron loss and, subsequently, lowered GAD/GABA levels. One form of acquired epilepsy resulting from interneuron loss is temporal lobe epilepsy (TLE) $[47,48]$. Furthermore, GABA-deficient epileptic syndromes also exist in genetic forms of epilepsy in humans or mice. Some examples include the following: 1) X-linked lissencephaly with abnormal genitalia, resulting from ARX (Aristaless Related Homeobox) mutations, with patients often displaying intractable epilepsy [49-51]; 2) DLX1 (Distal-less Homeobox 1) mutant mice [52]; 3) loss of GABApositive cortical interneurons in the UPAR (Urokinase Plasminogen Activator Receptor) knockout mouse [53,54]; and 4) dysregulated GABA-mediated synaptic inhibition as a result of disorganized hippocampal interneurons in Lis1 (Lissencephaly 1) mutant mice [55-58].

The goals of this study were to evaluate the effects of an acute administration of AG in mice and zebrafish larvae and to compare the behavioral, electrographic, and biochemical changes as well as the responses with pharmacological treatment with five mechanistically diverse AEDs in both species. If cross-species similarities in terms of seizure behavior and pharmacology are confirmed, we may conclude that the use of AG in zebrafish could allow high-throughput screening for novel small molecules targeting treatment-resistant seizures.

\section{Material and methods}

\subsection{Validation of the AG seizure model in mice}

\subsubsection{Animals}

Male NMRI mice (Charles River, France) weighing 20-32 g were used in all experiments. They were maintained on a 12/12-hour light/ dark cycle with lights on at 06:00 AM and had free access to food and drinking water. The temperature in the husbandry facility was maintained at $20-21^{\circ} \mathrm{C}$ and the humidity at about $40 \%$. For each experiment, the mice were housed in groups of 8-10 per cage and habituated for at least $1 \mathrm{~h}$ in the experimental room. All procedures were carried out according to the Declaration of Helsinki and conducted according to the guidelines of the European Community Council directive 86/609/EEC. Local Ethics Committees approved all performed experiments.

\subsubsection{Drug treatments}

(D,L)-Allylglycine (AG; Sigma), levetiracetam (LEV; UCB Pharma, Belgium), and sodium valproate (VPA; Sigma) were dissolved in $0.9 \%$ saline. Diazepam (DZP; Apin Chemicals), phenytoin (PHT; Fluka), and topiramate (TPM; UCB Pharma, Belgium) were suspended in $0.9 \%$ saline containing $0.1 \%$ Tween 80 . The injection volume was $10 \mathrm{ml} / \mathrm{kg}$ body weight. All AEDs were administered through the intraperitoneal (i.p.) route simultaneously or $90 \mathrm{~min}$ after AG injection. Antiepileptic drug pretreatment time points were chosen based on preliminary studies matching the onset of AG-induced seizures with the well-established pharmacokinetic profile of these AEDs in mice [59]. Control groups received the respective vehicle solution. Additionally, mortality was assessed in each group at $4 \mathrm{~h}$ and $24 \mathrm{~h}$ post-AG injection.

\subsubsection{AG dose-response curve}

Different groups of 10 mice were injected i.p. with increasing doses of AG ranging from 100 to $300 \mathrm{mg} / \mathrm{kg}$ and were placed in individual cages for a period of $3 \mathrm{~h}$ of observation. The mice first exhibited tremors and, sometimes, Straub tail, i.e., tail erected in a nearly vertical position, followed by myoclonus during the first hour postinjection. Later on, 
seizures were scored according to Racine's scale [60] with minor modifications [61]: stage 3 - repetitive forelimbs movements and head bobbing, stage 4 - clonus with rearing, and stage 5 - continuous rearing and falling.

\subsubsection{Electroencephalographic (EEG) recordings}

Each mouse was anesthetized with an i.p. injection of ketamine (Imalgen, $50 \mathrm{mg} / \mathrm{kg}$ ) and medetomidine (Domitor, $1 \mathrm{mg} / \mathrm{kg}$ ). Analgesia was provided with subcutaneous administration of $100 \mu$ of lidocaine (lignocaine, $2 \%$ as $\mathrm{HCl}$ salt) at the site of electrode implantation. The mouse was then secured in a stereotaxic frame, a skin incision was made, and small holes were drilled through the skull. Platinum electrode assembly was secured in place with dental cement (Caulk Dentsply, Milford, DE, USA). Electrodes (Supplementary Fig. 1B) were implanted into the right hippocampal CA1 area (bregma: $-1.94 \mathrm{~mm}$, lateral: $1.0 \mathrm{~mm}$, and depth: $-1.25 \mathrm{~mm}$ ), and surface electrodes were placed on the dura matter at the left frontal cortex level (bregma: $+1 \mathrm{~mm}$ and lateral: $+2 \mathrm{~mm}$ ) and at the occipital cortex level (bregma: $\pm 3 \mathrm{~mm}$ and lateral: $\pm 4 \mathrm{~mm}$ ). A recovery period of 2 weeks was allowed before EEG recordings were performed in freely moving mice during daylight time (between $8 \mathrm{AM}$ and $12 \mathrm{AM}$ ). Mice were injected i.p. with $275 \mathrm{mg} / \mathrm{kg}$ of AG and were placed in individual EEG cages for monitoring. The illustration of the video-EEG recording setup is shown in Supplementary Fig. 1A. Electroencephalographic signals were recorded in a frequency band of $1-35 \mathrm{~Hz}$ (Hertz) with 5000-gain factor (Grass software, Gamma 4.7).

\subsubsection{Data analysis and statistics}

Proportions of seizures and mortality were expressed as number of responding mice $(n)$ versus total number $(N)$ in each group of animals, and comparison between the vehicle-treated group and the drugtreated group was performed for each drug and dose using Fisher's exact probability test. For each tested drug, median as well as $25 \%$ and $75 \%$ percentiles for time to recurrent seizure onset were calculated for the tested dose, and statistical comparison versus the vehicle control group was obtained with a one-way ANOVA test followed by Dunn's comparison (GraphPad Prism 5, San Diego, CA).

\subsection{Validation of the AG seizure model in zebrafish larvae}

\subsubsection{Animals}

Fertilized zebrafish eggs of the wild-type $A B$ strain obtained by natural spawning were maintained at $28.5^{\circ} \mathrm{C}$ under constant light conditions in embryo medium (1.5-mM HEPES, pH 7.6, 17.4-mM NaCl, $0.21-\mathrm{mM} \mathrm{KCl}_{1} 0.12-\mathrm{mM} \mathrm{MgSO}_{4}$, and 0.18-mM Ca( $\left.\left.\mathrm{NO}_{3}\right)_{2}\right)$. Seven-dayold larvae were used in all experiments. All the experiments were conducted in accordance with the animal experimentation regulations of KU Leuven (ECD P101/2010).

\subsubsection{Drug treatments}

Allylglycine, levetiracetam, and topiramate were purchased from Sigma; other AEDs used in this study were the following: DZP (Roche), VPA (Sanofi-Aventis), and PHT (Acros). All compounds were dissolved in dimethylsulfoxide (DMSO) and were diluted in embryo medium to achieve a final DMSO concentration of $1 \%$ weight/volume $(w / v)$. Embryo medium prepared with DMSO to a final concentration of $1 \% \mathrm{w} / \mathrm{v}$ served as vehicle control (VHC).

\subsubsection{Locomotor tracking}

The larvae were placed individually in the wells of a 96-well plate; ten larvae were used per treatment group. Allylglycine was used in the concentration range of 30-300 mM; AEDs were tested at their respective maximal tolerated concentrations (MTCs): VPA $(0.5 \mathrm{mM})$, TPM $(200 \mu \mathrm{M})$, DZP $(16 \mu \mathrm{M}), \mathrm{LEV}(10 \mathrm{mM})$, and PHT $(100 \mu \mathrm{M})$; all were applied simultaneously with AG. Tolerability tests were performed as described previously [15]; briefly, touch response and posture abnormalities were scored after overnight exposure, and a concentration was considered unacceptable if more than 2 larvae out of 12 showed no touch response or died. As it is currently not possible to determine the amount of drug taken up in zebrafish larvae, we tested larval behavior both after a short (1-hour) and a long (overnight, 16-hour) exposure to determine whether there would be differences in uptake and potential toxicities upon longer exposure [15]. Behavioral analysis started within 5 min after AG application in the dark chamber of an automated tracking device (ZebraBox ${ }^{\mathrm{TM}}$ apparatus; Viewpoint, Lyon, France). Tracking time was $6 \mathrm{~h}$ or $8 \mathrm{~h}$. This extended monitoring period was carried out because for any given larva treated with $50-\mathrm{mM}$ or 70-mM AG, peak locomotor activity (total movement) was observed anywhere between $2 \mathrm{~h}$ and $7 \mathrm{~h}$. Each larva only showed one activity peak per 8-hour tracking period, and the time at which peak locomotor activity (per larva) could be observed during this 8-hour period was unpredictable. Thus, for consistency and comparison purposes, we chose the long tracking time of $8 \mathrm{~h}$ for all concentrations tested. This was also to determine whether any of the tested AEDs could prevent death or at least extend the period to death. At 300-mM AG, all larvae displayed convulsive behavior within $11 / 2$ to $2 \mathrm{~h}$ after administration. Since this time window was narrower and more predictive of when larvae would have seizures, we decided to use AG at 300 -mM for all subsequent experiments.

Locomotor activity was then quantified using ZebraLab ${ }^{\mathrm{TM}}$ software (Viewpoint, Lyon, France). Total movement or activity was expressed in "actinteg" units. The actinteg value of the ZebraLab ${ }^{\mathrm{TM}}$ software is defined as the sum of all image pixel changes detected during the time window defined for the experiment. When AEDs significantly decreased total AG-induced movement at their MTCs, a lower (1/2 MTC) concentration was tested as well. The lower effective concentrations were chosen for electrographic recordings in the case of VPA and DZP because of a prolonged survival time with AG at those concentrations compared with the higher ones.

\subsubsection{Electrographic recordings}

Each larva was incubated with $300-\mathrm{mM}$ AG in combination with AED or VHC for $2 \mathrm{~h}$ at room temperature $\left(20^{\circ} \mathrm{C}\right)$. A larva was then embedded in $2 \%$ low-melting-point agarose; a glass electrode filled with artificial cerebrospinal fluid (ACSF) composed of $124-\mathrm{mM} \mathrm{NaCl}$, 2-mM KCl, 2-mM $\mathrm{MgSO}_{4}, 2-\mathrm{mM} \mathrm{CaCl}_{2}, 1.25-\mathrm{mM} \mathrm{KH}_{2} \mathrm{PO}_{4}, 26-\mathrm{mM}$ $\mathrm{NaHCO}_{3}$, and 10-mM glucose (resistance: 1-5 $\mathrm{M} \Omega$ ) was placed into the optic tectum; and recordings were performed in current clamp mode, low-pass filtered at $1 \mathrm{kHz}$, high-pass filtered $0.1 \mathrm{~Hz}$, and digital gain 10 at sampling intervals of $10 \mu$ s (MultiClamp 700B Amplifier, Digidata 1440A Digitizer, both Axon instruments, USA). The recordings started each time exactly $5 \mathrm{~min}$ after the removal of the larva from treatment incubation solution and were continued for $10 \mathrm{~min}$.

Importantly, although larvae were embedded in low-melting point agarose, they were kept bathed in ACSF (see above) for the duration of the recordings, which were carried out only within the first 15 min postremoval from AG solution. These steps were taken so as to prevent potential artifacts. Moreover, spiking activities in controls were observed occasionally, but the patterns were considerably different from those observed for AG-treated larvae. These were characterized by single spikes of very short duration and have been described previously by Baraban and colleagues as bursts of synchronized activity [62].

Recordings from at least 10 larvae were taken per experimental condition. Importantly, in order to avoid any misinterpretation of the potential antiseizure effects of AED treatments, only the days of experiment where all AG-treated zebrafish larvae displayed recurrent seizures were taken into account. Spontaneous 10-min duration gap-free recordings were analyzed for all larvae $(n=72)$. A threshold for inclusion of AG-induced events was set at three times the background noise and 100-ms duration; all events exceeding these thresholds were analyzed. Electrophysiological recordings were analyzed post hoc in a single-blinded way using Clampfit 10.2 software (Molecular 
Devices Corporation, USA). Supplementary Fig. 2 depicts the setup used for local field potential recordings in zebrafish.

\subsubsection{GABA/glutamate determination}

Larvae were subjected to $300-\mathrm{mM} \mathrm{AG}$ for up to $120 \mathrm{~min}$. After the selected time, larvae were washed with ice-cold phosphate buffered saline (PBS), and their heads (6 per tube) were homogenized on ice for $1 \mathrm{~min}$ in $100 \mu \mathrm{l} 0.1$-M sodium acetate buffer $\mathrm{pH}$ 6.8. Homogenates were centrifuged at $15,000 \mathrm{~g}$ for $15 \mathrm{~min}$ at $4{ }^{\circ} \mathrm{C}$. Supernatants $(70 \mu \mathrm{l})$ were transferred to a clean tube and stored at $-70^{\circ} \mathrm{C}$.

The supernatant were diluted 50 times for the determination of GABA content by reverse-phase isocratic microbore LC with amperometric detection as described above. For glutamate analysis, the supernatant was diluted 5 times. We used a reverse-phase narrow bore assay with gradient elution and fluorescence detection. Fifteen microliters of the diluted supernatant were automatically derivatized with OPA in the presence of $\beta$-mercaptoethanol and also at $4{ }^{\circ} \mathrm{C}$ by a cooled ( 832 temperature regulator, Gilson, France) 231 XL sampling injector (Gilson, France). This one-step precolumn derivatization preceded the injection of $10 \mu \mathrm{l}$ of the sample on a C18 narrow bore column (5- $\mu \mathrm{m}$ particle size, $250 \times 2 \mathrm{~mm}$, Capcell Pak MG®, Shiseido). The samples were eluted by a Dionex P680 HPLC pump with the previously described mobile phases and gradient program [63]. Detection was performed with a RF 10A XL fluorescence detector (Shimadzu).

\subsubsection{Statistical analysis}

The effects of AEDs on AG-induced locomotion and changes in neurotransmitter levels were estimated using a one-way ANOVA followed by Dunnett's multiple comparison test. The effects of AEDs on electrographic activity were analyzed using the Student two-tailed unpaired $t$-test or the Mann-Whitney rank sum test for data that failed the normality test, as appropriate. The area of WISH staining in AG and AED-treated groups was compared with the one of VHC control in one-way ANOVA with subsequent Bonferroni posttest (GraphPad Prism 5, San Diego, CA).

\section{Results}

\subsection{AG dose-response profile in mice}

A clear progression in the number of mice exhibiting convulsions was observed with increasing doses of AG. The proportion of mice showing recurrent clonic seizures (stages 3-5 on modified Racine's scale $[60,61]$ ) increased from $60 \%$ at a dose of $225 \mathrm{mg} / \mathrm{kg}$ to $100 \%$ at the maximal tested dose of $300 \mathrm{mg} / \mathrm{kg}$. However, the latter dose was associated with high mortality (Fig. 1A). We selected the dose of $275 \mathrm{mg} / \mathrm{kg}$ for further investigation and AED testing. This dose induced recurrent seizures in about $90 \%$ of mice with limited mortality during the $3 \mathrm{~h}$ of observation. At that dose, the occurrence of myoclonic

\section{A}

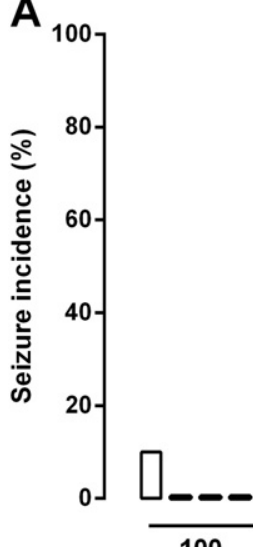

100
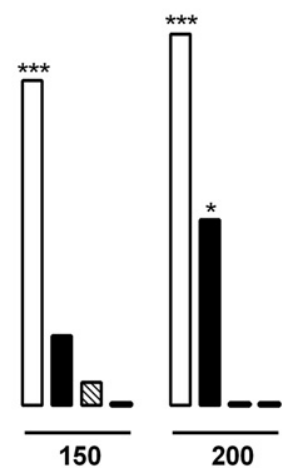

200

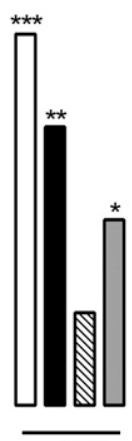

225

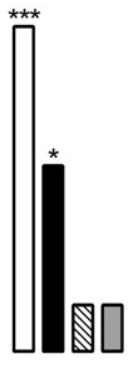

250

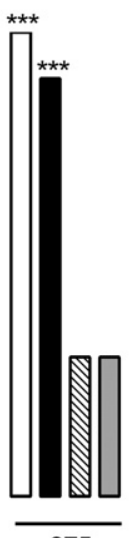

275

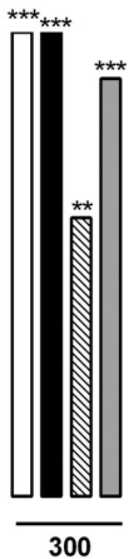

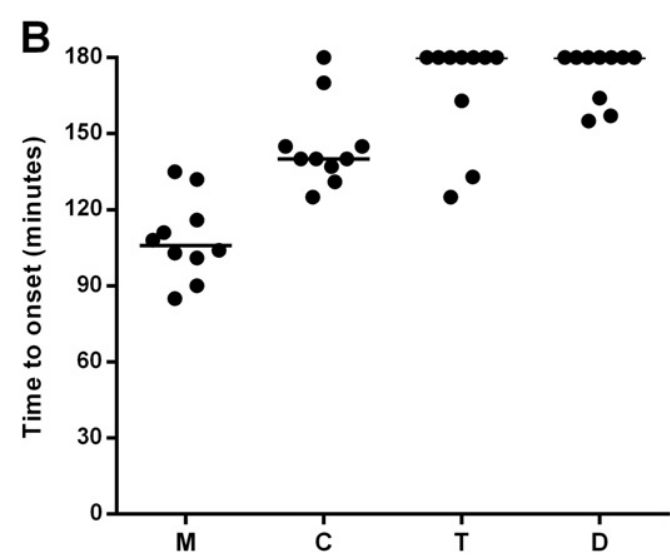

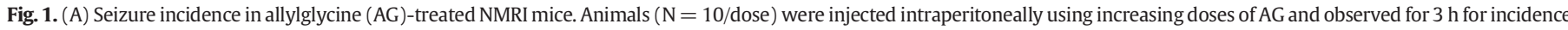

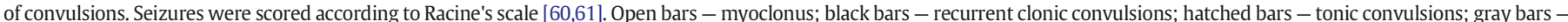

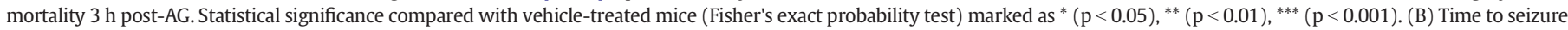

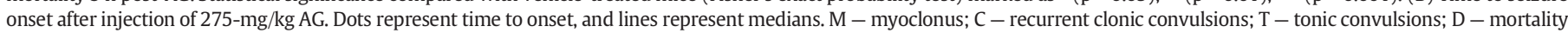
$3 \mathrm{~h}$ post-AG. 
convulsions (stage 2) started about 70 min postinjection and was followed by clonic convulsions, first in the forelimbs (stage 3 ) then evolving to clonus in all limbs with loss of balance (stages 4-5) [60] (Fig. 1B). Tonic convulsions were observed in about $30 \%$ of mice and were usually associated with mortality.

The mouse pharmacokinetic (PK) profile of AG in general matched the one described before in a previous study [38] (data not shown).

\subsection{Behavioral response of zebrafish larvae to $A G$}

Similar to mice, zebrafish larvae at 7 days postfertilization (dpf) displayed increased locomotor activity in response to various concentrations of AG. Behavioral manifestations followed the sequence and pattern (stages 1-3) described previously in zebrafish of this developmental stage [13], namely, increased swimming activity, followed by whole body convulsions and a subsequent loss of posture.

Pilot experiments showed that the locomotor hyperactivity of AGtreated larvae developed relatively slowly when compared with other proconvulsants (e.g., 20-mM pentylenetetrazol, PTZ) [13,15]. Allylglycine at $30 \mathrm{mM}$ did not induce changes in locomotor activity, with treated larvae exhibiting an identical level of total movement to that of VHCtreated controls within $6 \mathrm{~h}$ of tracking (data not shown). A range between 50-mM AG and 100-mM AG increased the overall motility of the larvae, though bursts of movement for individual larvae occurred asynchronously throughout the observation time. Locomotor hyperactivity of individual larvae peaked between $2.5 \mathrm{~h}$ and $8 \mathrm{~h}$ from the start of tracking. Exposure to this concentration range was relatively well tolerated, so that even at $100 \mathrm{mM}, 50$ to $80 \%$ of larvae were still alive at the end of each tracking session (Fig. 2 and data not shown).

At a higher concentration range (200- to 300-mM AG), latency time to increased locomotor activity was significantly shortened. In contrast to the lower concentrations of AG tested, peaks in locomotor activity became more synchronized although their amplitudes followed a downward trend. This period of increased motility was followed by an irreversible decline in locomotion and subsequent death of all larvae from $3 \mathrm{~h}$ onward of an 8-hour total observation period (Fig. 2).

Comparison of results between mice and zebrafish showed that seizure onset occurred in both species after a similar latency time. This latency period was described previously in mice (44-240 min) and in rats (120-150 min) by Horton and Meldrum [41] and Alberici et al. [64], respectively. A wide variation in seizure onset between test animals was also reported by these authors. In AG-injected mice (i.p., $115-\mathrm{mg} / \mathrm{kg}$ AG, dose inducing convulsions in $50 \%$ of mice), seizures were described to begin after $2-4 \mathrm{~h}$, recur for $1-2 \mathrm{~h}$, and lead to death in 2 out of 5 animals having convulsions. We observed a comparable convulsive profile in mice but were able to use a higher dose of AG (dose inducing $90 \%$ of recurrent seizures) for testing of AEDs. In zebrafish, convulsive behaviors were observed for the majority of larvae within 1.5 to $2 \mathrm{~h}$ of bathing in 300-mM AG. Similar to rodents, increasing the dose shortened the latency to death more than the latency to seizures [41].

\subsection{Electrographic brain activity in AG-treated mice}

Electroencephalographic activity recorded in mice following acute AG injection (275 mg/kg, i.p.) showed typical spike-wave discharges starting in the hippocampus from $2 \mathrm{~h}$ postinjection. Ictal activity was observed during each episode of clonic convulsions (e.g., $t=136$ and $\mathrm{t}=187$ min postinjection; Fig. 3 ), which appeared to spread from the hippocampus to the cortex. Suppression of EEG amplitude with very few isolated spikes was also observed between such seizure episodes (e.g., $\mathrm{t}=162 \mathrm{~min}$; Fig. 3). This pattern of evolution of electrographic activity is comparable with that described for other chemoconvulsants, e.g., kainate or 4-aminopyridine, but ictal events appear much later after administration of AG [65,66].
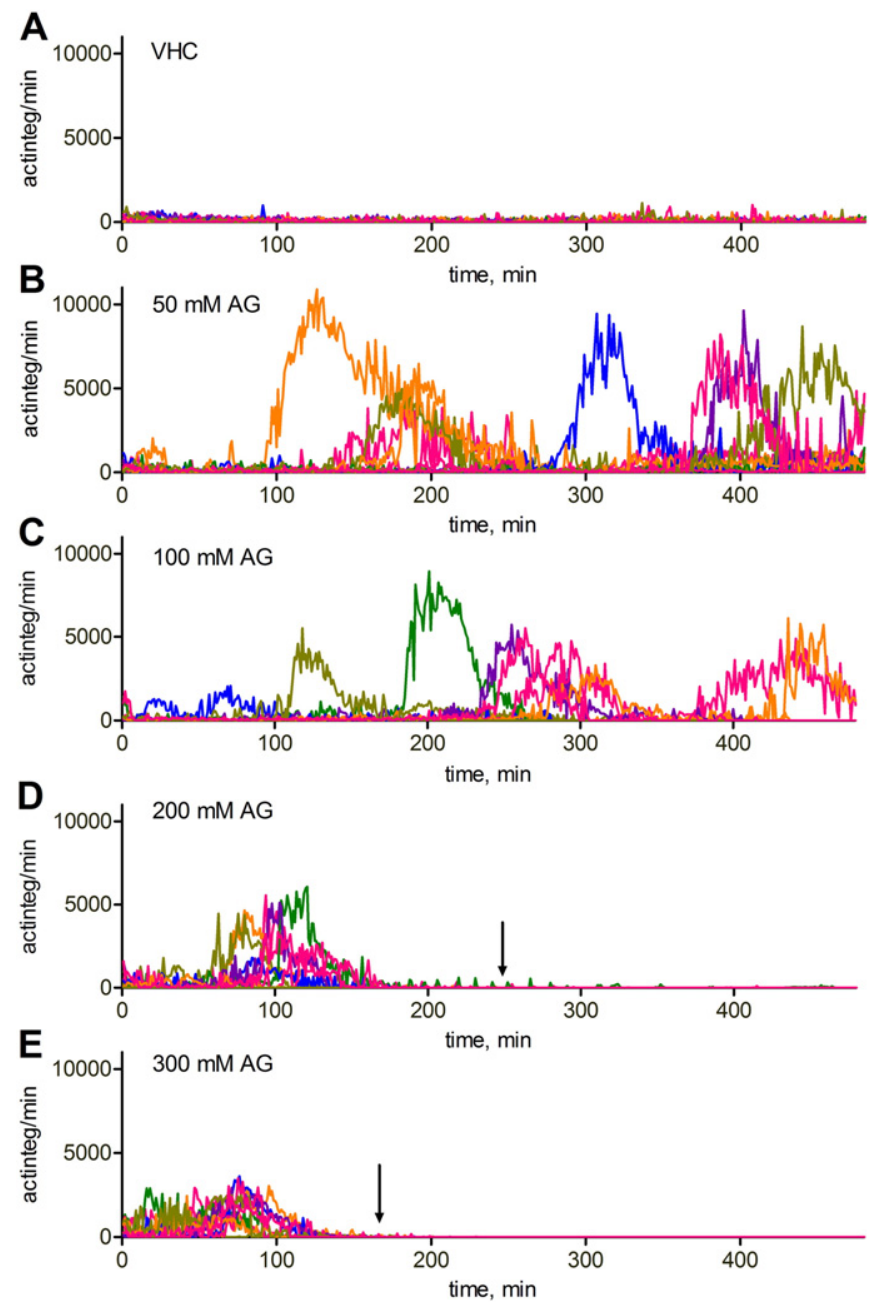

Fig. 2. Effects of allylglycine (AG) on locomotor activity of zebrafish larvae. Time-course of locomotor activity (actinteg units/min) of individual larvae shown in different colors; curves of 10-12 larvae from one treatment group plotted together, representative experiments shown. (A) VHC, (B) 50-mM AG, (C) 100-mM AG, (D) 200-mM AG, and (E) 300-mM AG. Arrows indicate the time points when $50 \%$ of the fish in the group died.

\subsection{Electrographic brain activity in AG-treated zebrafish larvae}

To confirm that application of 300-mM AG resulted in abnormal brain activity in zebrafish, we performed local field potential recordings from 7-dpf larval optic tecta. Epileptiform paroxysmal events consisted of polyspiking discharges (PDs) with amplitudes equal to or exceeding threefold baseline and were detected starting from the range of 90120 min of AG exposure onwards. Such recurrent, induced epileptiform events occurred in the vast majority of larvae at a mean frequency of $16.4 \pm 3.7$ events/10-min recording. The mean duration of epileptiform events was $671 \pm 23 \mathrm{~ms}$ ( $\mathrm{n}=14$ fish, 230 events analyzed, data not shown).

\subsection{Neurotransmitter levels in AG-treated zebrafish}

The concentration of GABA remained at the level of untreated larvae until 20 min following 300-mM AG exposure. A slight downward trend in GABA levels was first observed at $40 \mathrm{~min}$ and became significantly lower (one-way ANOVA) than at time point zero starting from $60 \mathrm{~min}$ onwards (Fig. 4A). The levels of glutamate did not significantly change at the time points tested. The GABA/glutamate ratio dropped 


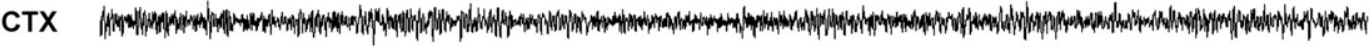
Baseline

HPC

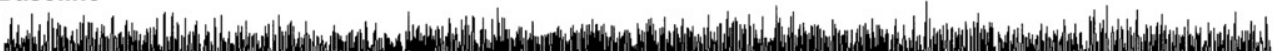
WH

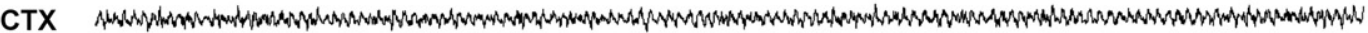
60 minutes

HPC

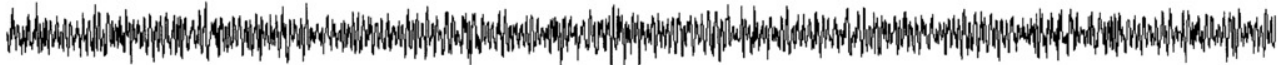

CTX

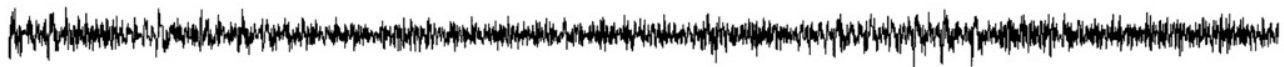
120 minutes

HPC

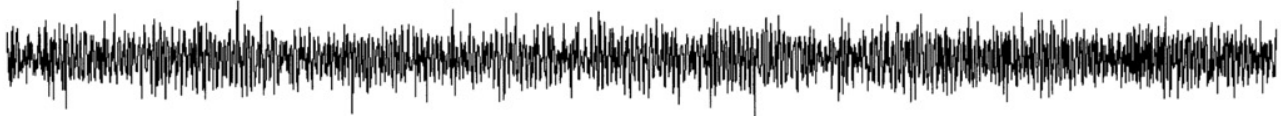

CTX

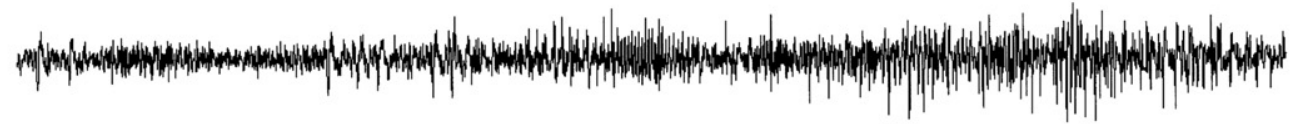
136 minutes HPC

CTX

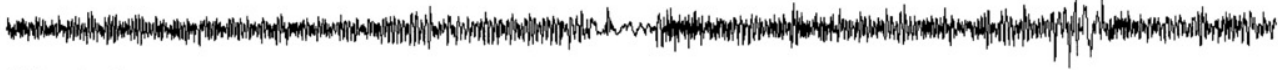
162 minutes

HPC

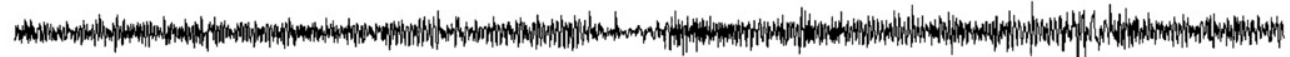
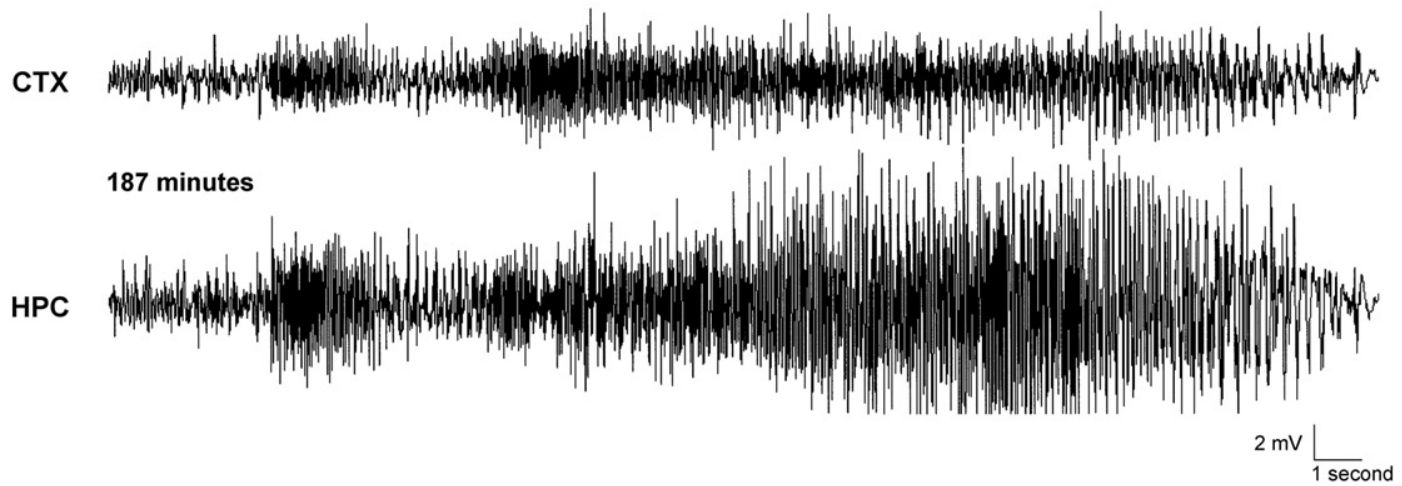

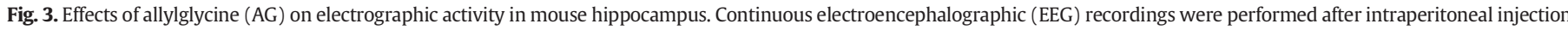
of $275 \mathrm{mg} / \mathrm{kg}$ of AG. CTX - left frontal cortical electrode; HPC - hippocampal electrode.

significantly below baseline at the 90 - and 120 -min time points (Fig. 4B), which matches with the time frame of epileptiform activity occurrence in the tectal field recordings.

Despite different administration routes used for AG (i.p. injection in mice versus bath exposure in zebrafish larvae), the time-course of GABA depletion in zebrafish matched with the residual activity of GAD estimated in mice previously by Horton and Meldrum [41] (at the dose of $200-\mathrm{mg} / \mathrm{kg} \mathrm{AG}$, in BALB/C mice, GAD activity dropped by about $35 \%$ of the initial values at 90 min post-AG injection followed by seizures in the span of 95-180 min post-AG dose). 
A

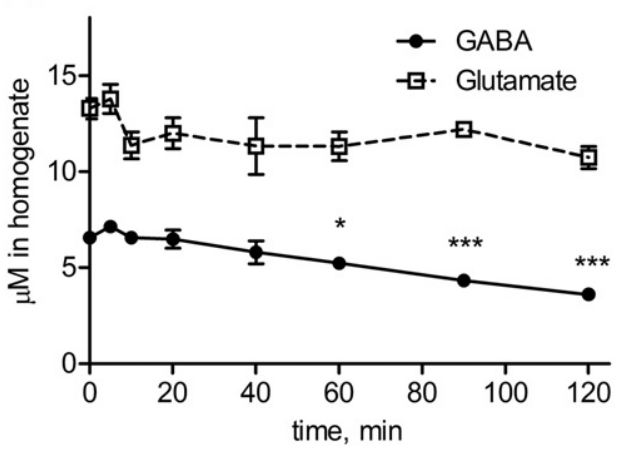

B

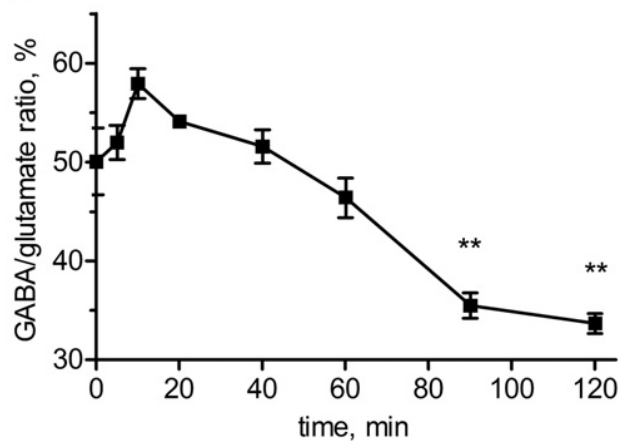

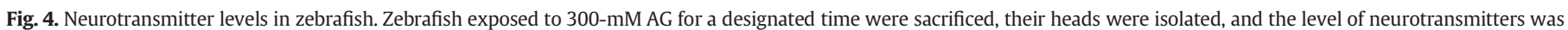

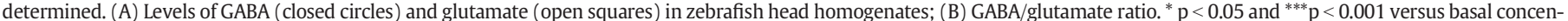
tration (one-way ANOVA). Error bars show SEM.

\subsection{Effects of AEDs on AG-induced convulsions in mice}

We tested five mechanistically diverse AEDs that were administered at two different time points in relation to AG injection. Because of the abovementioned long latency to seizure onset after AG injection, we administered these compounds either simultaneously with AG or 90 min later.
Valproate dose-dependently decreased the proportion of mice exhibiting recurrent seizures (Table 1 ); this effect was statistically significant at $299 \mathrm{mg} / \mathrm{kg}$ when VPA was injected 90 min post-AG $(275 \mathrm{mg} / \mathrm{kg}$ ), and the time to seizure onset was significantly increased (Table 1). Valproate also delayed onset but did not protect against mortality with a significant effect observed at $166 \mathrm{mg} / \mathrm{kg}$ when administered 90 min post-AG (Table 1 ).

Table 1

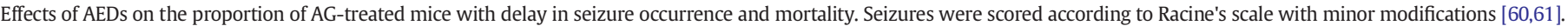

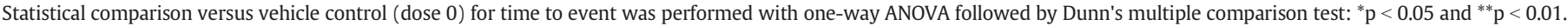

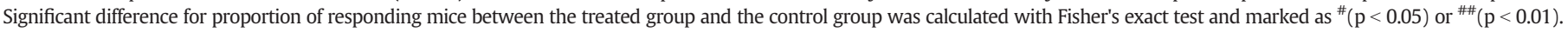
A dose of $275 \mathrm{mg} / \mathrm{kg}$ AG was used.

\begin{tabular}{|c|c|c|c|c|c|c|c|c|c|}
\hline Drug & $\begin{array}{l}\text { Doses } \\
(\mathrm{mg} / \mathrm{kg})\end{array}$ & $\begin{array}{l}\text { Time } \\
\text { post-AG inj. } \\
(\mathrm{min})\end{array}$ & $\begin{array}{l}\text { Myoclonus } \\
\mathrm{n} / \mathrm{N}\end{array}$ & $\begin{array}{l}\text { Time to } \\
\text { myoclonus } \\
(\min )\end{array}$ & $\begin{array}{l}\text { Recurrent } \\
\text { clonus } \\
\mathrm{n} / \mathrm{N}\end{array}$ & $\begin{array}{l}\text { Time to recurrent } \\
\text { clonus (min) }\end{array}$ & $\begin{array}{l}\text { Mortality at } 4 \mathrm{~h} \\
\text { post-AG inj. } \\
\mathrm{n} / \mathrm{N}\end{array}$ & $\begin{array}{l}\text { Time to mortality } \\
\text { (min) }\end{array}$ & $\begin{array}{l}\text { Mortality at } 24 \mathrm{~h} \\
\text { post-AG inj. } \\
\mathrm{n} / \mathrm{N}\end{array}$ \\
\hline \multirow[t]{6}{*}{ VPA } & 0 & 0 & $9 / 10$ & $109(94-163)$ & $7 / 10$ & $150(134-240)$ & $8 / 10$ & $177(148-238)$ & $8 / 10$ \\
\hline & 166 & & $10 / 10$ & $175(121-193)$ & $6 / 10$ & $221(184-240)$ & $4 / 10$ & $240(199-240)$ & $6 / 10$ \\
\hline & 299 & & $8 / 10$ & $183(169-226)^{*}$ & $4 / 10$ & $240(227-240)^{*}$ & 0/10\#\# & $240(240-240)^{* *}$ & $6 / 10$ \\
\hline & 0 & 90 & $8 / 8$ & $85(78-101)$ & $8 / 8$ & $104(101-108)$ & $8 / 8$ & $128(116-140)$ & $8 / 8$ \\
\hline & 166 & & $8 / 8$ & $94(78-140)$ & $7 / 8$ & $166(152-190)^{*}$ & $1 / 8 \# \#$ & $240(240-240)^{* *}$ & $8 / 8$ \\
\hline & 299 & & $8 / 8$ & $88(78-95)$ & 4/8\# & $223(155-240)^{* *}$ & $1 / 8 \# \#$ & $240(240-240)^{* *}$ & $7 / 8$ \\
\hline \multirow[t]{8}{*}{ LEV } & 0 & 0 & $17 / 18$ & $100(94-112)$ & $17 / 18$ & $129(120-156)$ & $15 / 18$ & $174(149-227)$ & $18 / 18$ \\
\hline & 306 & & $8 / 8$ & $164(142-184)^{*}$ & $8 / 8$ & $206(197-226)^{*}$ & 1/8\#\# & $240(172-240)$ & $5 / 8$ \\
\hline & 544 & & $16 / 18$ & $145(112-155)$ & $15 / 18$ & $167(144-210)$ & $9 / 18 \#$ & $237(213-240)^{*}$ & $16 / 18$ \\
\hline & 953 & & $17 / 18$ & $149(112-184)^{*}$ & 12/18\# & $216(165-240)^{* *}$ & 0/18\#\# & $240(240-240)^{* *}$ & $16 / 18$ \\
\hline & 0 & 90 & $8 / 8$ & $96(95-101)$ & $8 / 8$ & $117(106-144)$ & $8 / 8$ & $143(132-163)$ & $8 / 8$ \\
\hline & 306 & & $8 / 8$ & $93(80-102)$ & $8 / 8$ & $123(114-134)$ & $8 / 8$ & $140(130-172)$ & $8 / 8$ \\
\hline & 544 & & $8 / 8$ & $108(95-139)$ & $8 / 8$ & $133(111-150)$ & $7 / 8$ & $183(117-194)$ & $8 / 8$ \\
\hline & 953 & & $8 / 8$ & $109(81-115)$ & $8 / 8$ & $132(124-170)$ & $4 / 8 \#$ & $237(168-240)$ & $7 / 8$ \\
\hline \multirow[t]{8}{*}{ PHT } & 0 & 0 & $16 / 18$ & $104(84-145)$ & $14 / 18$ & $164(123-187)$ & $15 / 18$ & $171(147-223)$ & $18 / 18$ \\
\hline & 25 & & $5 / 8$ & $179(138-240)$ & $4 / 8$ & $216(151-240)$ & 0/8\#\# & $240(240-240)^{* *}$ & $5 / 8 \#$ \\
\hline & 45 & & $5 / 8$ & $158(123-240)$ & $4 / 8$ & $222(154-240)$ & $0 / 8 \# \#$ & $240(240-240)^{* *}$ & $2 / 8 \# \#$ \\
\hline & 81 & & $18 / 18$ & $103(83-146)$ & $15 / 18$ & $188(145-216)$ & 2/18\#\# & $240(240-240)^{* *}$ & $12 / 18$ \\
\hline & 0 & 90 & $8 / 8$ & 99 (95-119) & $8 / 8$ & $125(106-156)$ & $7 / 8$ & $167(136-214)$ & $8 / 8$ \\
\hline & 25 & & $8 / 8$ & $98(93-106)$ & $8 / 8$ & $127(103-153)$ & $3 / 8$ & $240(196-240)$ & $8 / 8$ \\
\hline & 45 & & $8 / 8$ & $103(94-114)$ & $8 / 8$ & $136(128-170)$ & $2 / 8 \#$ & $240(238-240)^{* *}$ & $7 / 8$ \\
\hline & 81 & & $8 / 8$ & $106(87-112)$ & $8 / 8$ & $156(116-171)$ & $4 / 8$ & $238(225-240)$ & $6 / 8$ \\
\hline \multirow[t]{8}{*}{ TPM } & 0 & 0 & $8 / 8$ & $107(87-150)$ & $6 / 8$ & $156(130-227)$ & $3 / 8$ & $240(167-240)$ & $6 / 8$ \\
\hline & 34 & & $8 / 8$ & $124(116-149)$ & $4 / 8$ & $226(181-240)$ & $2 / 8$ & $240(240-240)$ & $8 / 8$ \\
\hline & 109 & & $7 / 8$ & $149(101-224)$ & $4 / 8$ & $222(164-240)$ & $3 / 8$ & $240(183-240)$ & $4 / 8$ \\
\hline & 340 & & $6 / 8$ & $173(110-236)$ & $4 / 8$ & $236(176-240)$ & $0 / 8$ & $240(240-240)$ & $1 / 8 \#$ \\
\hline & 0 & 90 & $8 / 8$ & $112(103-124)$ & $8 / 8$ & $155(139-160)$ & $7 / 8$ & $227(203-237)$ & $7 / 8$ \\
\hline & 34 & & $8 / 8$ & $114(95-157)$ & $5 / 8$ & $169(149-240)$ & $4 / 8$ & $225(175-240)$ & $6 / 8$ \\
\hline & 109 & & $7 / 8$ & $130(115-158)$ & $6 / 8$ & $187(157-228)$ & 0/8\#\# & $240(240-240)^{* *}$ & $2 / 8 \#$ \\
\hline & 340 & & $7 / 8$ & $105(93-178)$ & $5 / 8$ & $189(159-240)$ & $0 / 8 \# \#$ & $240(240-240)^{* *}$ & $0 / 8 \# \#$ \\
\hline \multirow[t]{8}{*}{ DZP } & 0 & 0 & $8 / 8$ & $90(74-178)$ & $6 / 8$ & $137(121-219)$ & $6 / 8$ & $148(126-220)$ & $6 / 8$ \\
\hline & 1.6 & & $8 / 8$ & $124(102-177)$ & $6 / 8$ & $165(156-227)$ & $3 / 8$ & $240(216-240)$ & $8 / 8$ \\
\hline & 2.9 & & $6 / 8$ & $192(144-235)$ & $2 / 8$ & $240(227-240)^{*}$ & $0 / 8 \# \#$ & $240(240-240)^{* *}$ & $6 / 8$ \\
\hline & 5.1 & & $3 / 8 \#$ & $240(198-240)^{* *}$ & $1 / 8 \#$ & $240(240-240)^{* *}$ & $0 / 8 \# \#$ & $240(240-240)^{* *}$ & $5 / 8$ \\
\hline & 0 & 90 & $8 / 8$ & $102(86-116)$ & $6 / 8$ & $127(103-214)$ & $5 / 8$ & $211(145-240)$ & $7 / 8$ \\
\hline & 1.6 & & $7 / 8$ & $159(77-213)$ & $1 / 8 \#$ & $240(240-240)$ & $1 / 8$ & $240(240-240)$ & $4 / 8$ \\
\hline & 2.9 & & 4/8\# & $165(79-240)$ & $1 / 8 \#$ & $240(240-240)^{*}$ & $0 / 8 \#$ & $240(240-240)^{*}$ & $2 / 8 \#$ \\
\hline & 5.1 & & $2 / 8 \# \#$ & $240(128-240)$ & $0 / 8 \# \#$ & $240(240-240)^{* *}$ & $0 / 8 \#$ & $240(240-240)^{*}$ & $0 / 8 \# \#$ \\
\hline
\end{tabular}


Levetiracetam and phenytoin reduced the proportion of mice exhibiting recurrent seizures when administered simultaneously with AG (Table 1) but were completely ineffective when administered at 90 min post-AG. These two AEDs are usually tested in acute models at 60 and $120 \mathrm{~min}$, respectively [59], for optimal efficacy. Levetiracetam was also able to prolong the latency time to seizure incidence (Table 1). Phenytoin and, to a lower extent, LEV delayed the occurrence of mortality, with a decrease in mortality still observed $24 \mathrm{~h}$ after AG but only at $306 \mathrm{mg} / \mathrm{kg}$ for LEV (Table 1). The lower efficacy of PHT at $81 \mathrm{mg} / \mathrm{kg}$, which is likely due to decreased tolerability at this high dose, is worth noting.

In contrast, TPM did not show a significant effect against seizure incidence or time to onset (Table 1 ) but delayed mortality with maximal efficacy when administered 90 min post-AG. The mortality was dosedependently decreased with a maximal effect observed when TPM was administered 90 min post-AG (Table 1 ).

In our hands, the most efficacious AED was DZP, which completely abolished seizure occurrence at the highest tested dose $(5.1 \mathrm{mg} / \mathrm{kg})$ when administered 90 min post-AG (Table 1). The lower doses (1.6 and $2.9 \mathrm{mg} / \mathrm{kg}$ ) significantly decreased clonic seizure incidence and also significantly increased the time to seizure onset. Diazepam significantly delayed the 4-hour mortality incidence in both regimens of administration (Table 1) and significantly decreased the 24-hour mortality when administered 90 min post-AG. It is worth noting that the doses used in mice in the case of TPM and PHT were close to their $\mathrm{TD}_{50}$ values (doses inducing motor impairment in $50 \%$ of naïve mice) estimated in the rotarod test (data not shown). Reported $\mathrm{TD}_{50}$ doses in the rotarod test are $398-465 \mathrm{mg} / \mathrm{kg}$ for VPA, $41-70 \mathrm{mg} / \mathrm{kg}$ for PHT, $>500 \mathrm{mg} / \mathrm{kg}$ for LEV, $318-401 \mathrm{mg} / \mathrm{kg}$ for TPM, and $6.8 \mathrm{mg} / \mathrm{kg}$ for DZP, respectively $[59,67]$.

Overall, efficacy of AEDs was rather limited in our experimental setup. In the mouse assays, no complete seizure suppression at the chosen doses was achieved, and the animals were only protected against mortality at doses close to sedative ones, i.e., PHT at $45 \mathrm{mg} / \mathrm{kg}$, diazepam at $2.9 \mathrm{mg} / \mathrm{kg}$, and TPM at $109 \mathrm{mg} / \mathrm{kg}$.

\subsection{Effects of AEDs on AG-induced behavioral changes and electrographic seizures in zebrafish}

In experiments wherein 300-mM AG was coadministered with AEDs at their respective MTCs, VPA and DZP decreased larval locomotor activity levels significantly (Fig. 5A). Topiramate also showed partial suppression of larval movement, while LEV and PHT showed no activity. Additional experiments showed that VPA and DZP were also active at a lower concentration (1/2 MTC; data not shown), which was chosen for electrographic recordings due to prolonged survival time. The effect of TPM was significant only at MTC and did not increase further at a higher concentration (data not shown).

In order to confirm that the larval locomotor response to AEDs corresponded to an effect on seizure activity, the occurrence of epileptiform discharges was then examined in larvae coincubated with AEDs and $300 \mathrm{mM}$ AG for $2 \mathrm{~h}$. Application of VHC was used as a negative control. Coapplication of 300-mM AG and DZP ( $8 \mu \mathrm{M}, \mathrm{n}=10$ fish) or VPA ( $250 \mu \mathrm{M} ; \mathrm{n}=13$ fish), PHT (100 $\mu \mathrm{M} ; \mathrm{n}=13$ fish), and TPM $(200 \mu \mathrm{M}$; $\mathrm{n}=11$ fish) decreased the occurrence of epileptic events compared with 300-mM AG incubated with vehicle (Fig. 5B; AG + VHC: $16.4 \pm$ 3.7 versus $A G+V P A: 2 \pm 0.9, A G+D Z P: 1.6 \pm 1.5$, AG + PHT: $8.7 \pm 4.4$ and $\mathrm{AG}+$ TPM: $4.5 \pm 1.7$ events/10-min recording; $\mathrm{p}=$ $0.0002, \mathrm{p}=0.0002, \mathrm{p}=0.0357$ and $\mathrm{p}=0.0081$, respectively). Only LEV showed no significant effect on the occurrence of epileptiform events (Fig. 5B, LEV; $10 \mathrm{mM}, \mathrm{n}=11$ fish, AG + VHC: $16.4 \pm 3.7$ versus LEV: $10.5 \pm 2.9$ events/ 10 -min recording, $\mathrm{p}=0.2315$ ). Similarly, the cumulative duration of epileptiform events, i.e., the fraction of time spent in epileptic activity, was significantly decreased for all treatments except LEV (Fig. 5C; AG + VHC: 11,031 \pm 2799 versus AG + VPA: $407 \pm 185$, AG + DZP: $1555 \pm 1505$, AG + LEV: $6292 \pm 1803$, AG + PHT: $3140 \pm 1517$, and AG + TPM: $1577 \pm 634 \mathrm{~ms} / 10$-min recording, $\mathrm{p}<0.0001, \mathrm{p}=0.0007, \mathrm{p}=0.1947, \mathrm{p}=0.0048$, and $\mathrm{p}=0.0052$, respectively). Representative recordings of electrographic activities in seizurefree larvae are shown as examples for DZP (Fig. 6B) and VPA (Fig. 6C). Importantly, none of the treatments afforded complete seizure protection in the given time frame - i.e., neither prevention nor delay in mortality of zebrafish larvae was achieved (data not shown).

\section{Discussion}

In general, AED ability (or inability) to suppress convulsions in mice correlated well with the data obtained for the larval locomotor response, even though AEDs were evaluated at their $\mathrm{TD}_{50}$ or MTC, respectively. In summary, VPA and DZP were active in both species with TPM, PHT, and LEV showing limited to no protection against seizures. More specifically, TPM showed partial protection in the locomotor and electrographic assays in zebrafish but not in mice; the activity of PHT could only be observed in the electrographic assay in zebrafish, and LEV increased the latency time to seizures solely in mice (Table 1). These findings are in line with the clinical definition of drug-resistant epilepsy described as the failure of at least two medications to exhibit full control of seizures, i.e., seizure freedom [68].
A

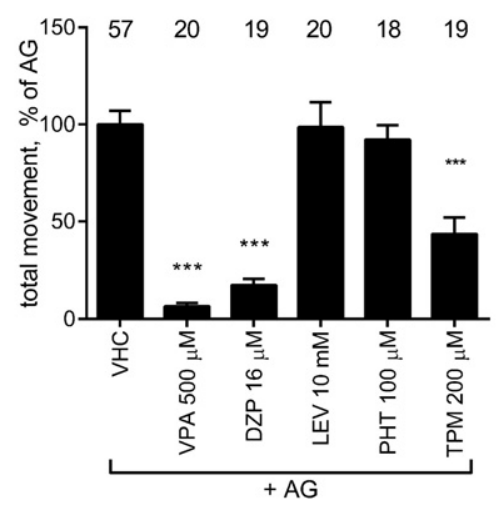

B

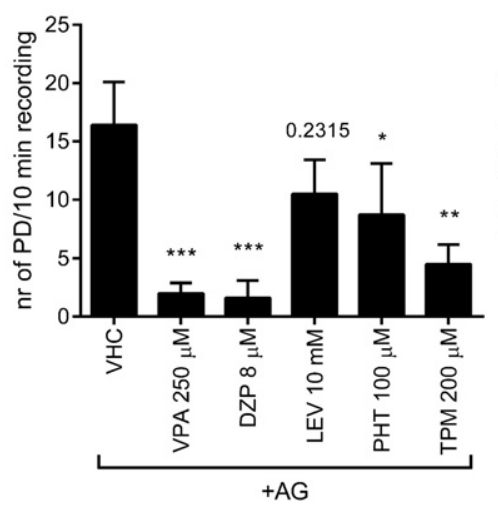

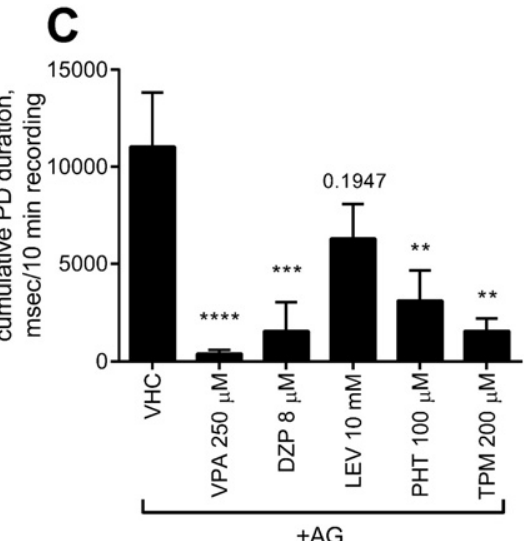

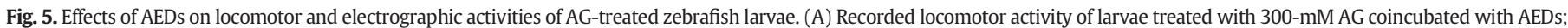

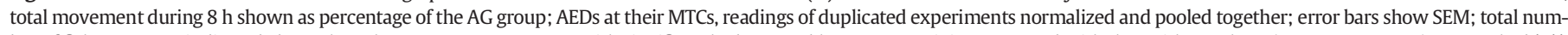

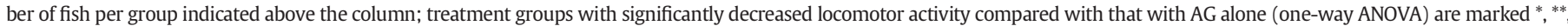

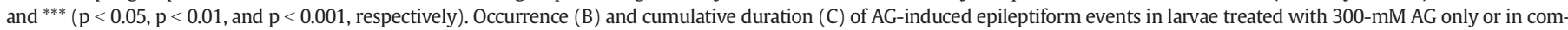

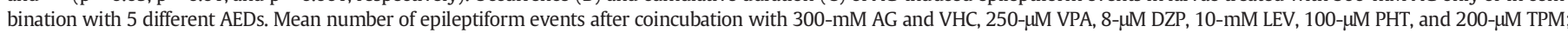

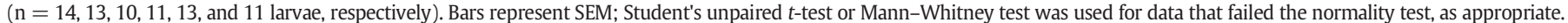


A

$$
A G 300 \mathrm{mM}+\mathrm{VHC}
$$

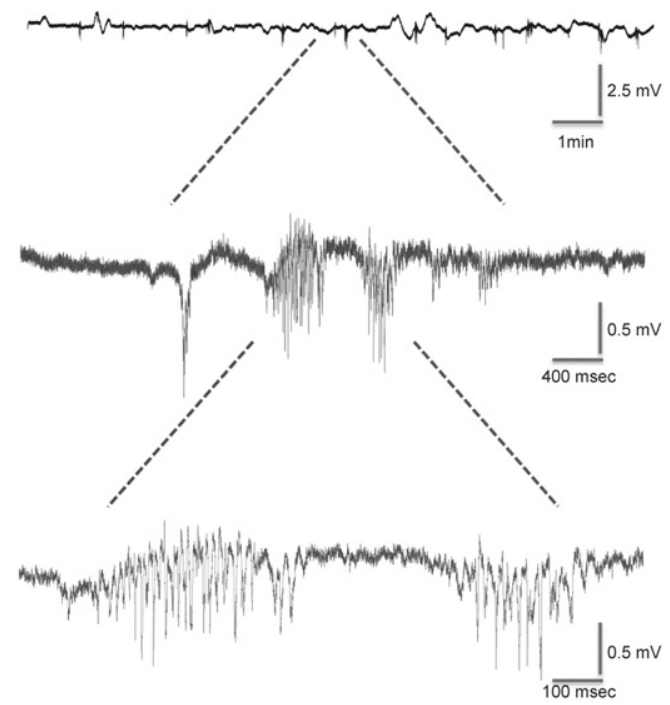

B

$A G 300 \mathrm{mM}+\mathrm{DZP} 8 \mu \mathrm{M}$

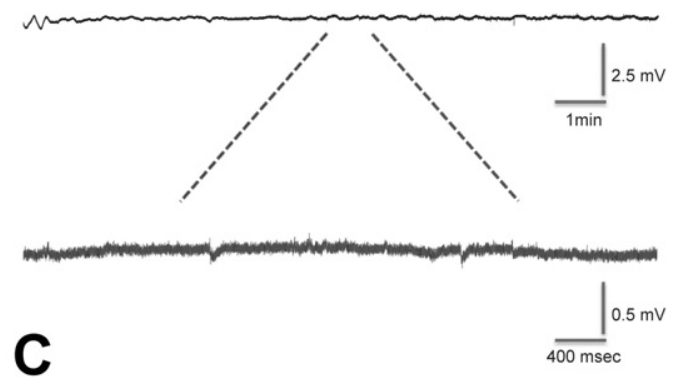

$A G 300 \mathrm{mM}+\mathrm{VPA} 250 \mu \mathrm{M}$

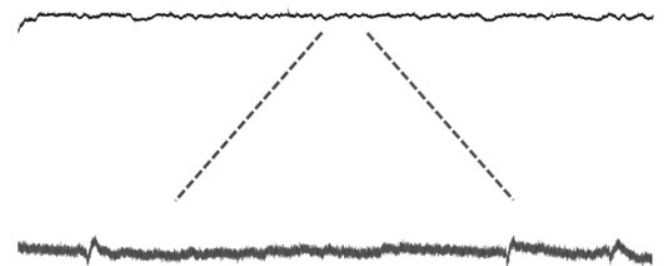

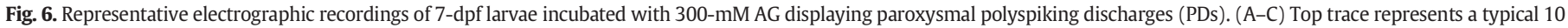

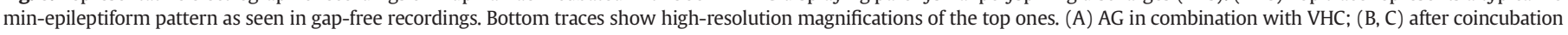
with 300-mM AG and (B) 8- $\mu \mathrm{M}$ DZP or (C) 250- $\mathrm{MM}$ VPA. The scales for B and C are the same.

Despite the clear advantages of using embryonic and larval zebrafish over adults for drug screening, the potential drawbacks and limitations must also be taken into consideration. For example, incompletely developed brain regions may limit the aspects of a neurological disorder that can be studied. Moreover, the larval zebrafish blood-brain barrier is still largely permeable until $10 \mathrm{dpf}$. Therefore, proper assessment of drug uptake into the brain from the circulation and subsequent extrapolation of appropriate dosage and uptake in mammals are currently not possible. In addition, some compounds or drugs have proven insoluble in water (our own observations), thus once again preventing quantification of drug uptake and possibly leading to false negatives. In the latter instance, we were able to circumvent this solubility problem by improving the low bioactivity of a compound through microinjection into the blood circulation after solubilization in 50\% DMSO. Surprisingly, zebrafish embryos were able to survive such high concentrations of DMSO solvent quite well [69].

Glutamic acid decarboxylase is a rate-limiting enzyme in the GABA synthesis pathway; it acts by metabolizing glutamate into GABA, thus directly influencing GABA concentration. Allylglycine-mediated GAD inhibition could, in part, be due to its metabolite 2-keto-4-pentenoic acid, which is a more potent blocker of cerebral GAD activity than AG $[37,70]$. Furthermore, a few models of focal epilepsy are also based on impaired GABAergic activity, such as hyperbaric oxygen or glutaric acidemia [71, 72]. Similarly, a compound restoring cerebral GABA concentration (gabaculine) [71] is not sufficient per se to protect against seizure occurrence, suggesting that other pathways could also be involved. Thus, such a screening model will likely be capable of identifying compounds with different mechanisms of action. According to the data from patients with epilepsy, GAD activity is decreased in the cortex [36], and upregulation of GAD isoforms (GAD65 and GAD67) has been described in the remaining GABAergic neurons in a model of temporal lobe epilepsy [73]. Moreover, GAD autoantibodies have been detected in patients with treatment-refractory epilepsy [74]. These findings, therefore, support the usefulness of animal models modulating GAD activity for preclinical work in the context of epilepsy.

The mechanism of action of AG, namely, impairment of GABA biosynthesis through GAD inhibition, presumably suggests a particular pharmacological profile of this model. Reduced GABA concentrations in the brain have been shown to induce convulsions and are associated with neuronal damage [75]. The imbalance between excitatory and inhibitory pathways has been associated with status epilepticus therapyresistant seizures [76]. Indeed, classical preclinical seizure screening models typically target $\mathrm{GABA}_{\mathrm{A}}$ receptors (e.g., PTZ, bicuculline, and picrotoxin), but no model currently used widely inhibits GABA biosynthesis. Comparing the pharmacological profiles of classical models (Table 2) with the profile of AG, we see not only a partial overlap but also unique seizure responsiveness/resistance combinations in each case.

Other potential perspectives of the AG model are based on the observations that at subconvulsive doses, AG produces an anxiety-like state and increases vulnerability to panic attacks in animals and humans, suggesting the added involvement of the serotoninergic system [81]. Several other modulatory actions on the GABA pathway were described and associated with behavioral manifestations. For example, the disruption of GABAergic inhibition by a reverse $\mathrm{GABA}_{\mathrm{A}}$ receptor agonist (FG-7142) elicited $c$-fos expression changes in the orexin neuron hypothalamic network involved in stress and panic [82]. An important role for the GABAergic system has also been reported in the context of hallucinations [83]. Altogether, these mechanisms may possibly lead to the development of a multiindication drug discovery assay.

\section{Conclusions}

In the course of this study, we have confirmed the biochemical and encephalographic (EEG) changes induced by AG treatment in mice. We also report for the first time the use of AG for the induction and monitoring of acute seizures in zebrafish. Moreover, we assessed the efficacy and potency of five first-line AEDs against AG-induced convulsions. Protective effects were observed at relatively high doses only for two out of five AEDs. Given that more than half of AEDs showed partial to no seizure protection, the AG seizure model illustrates treatment resistance to certain AEDs with specific modes of action and is in line with the ILAE definition of therapy resistance in patients with epilepsy. Finally, having demonstrated a high degree of cross-species similarities for this acute AG seizure model, we propose the use of zebrafish for the 
Table 2

Efficacy of some AEDs in acute seizure tests involving the GABAergic system.

\begin{tabular}{|c|c|c|c|}
\hline Treatment & Animal & Responder to & Resistant to \\
\hline AG (present manuscript) & Mice, fish & Valproate, diazepam & Levetiracetam, phenytoin, topiramate ${ }^{1}$ \\
\hline PTZ $[15,77,78]$ & Mice, fish & $\begin{array}{l}\text { Phenobarbital, valproate, diazepam, ethosuximide, gabapentin }{ }^{2} \text {, } \\
\text { levetiracetam }^{3}\end{array}$ & Phenytoin, carbamazepine, topiramate, lamotrigine \\
\hline Bicuculline $[78,79]$ & Mice & Diazepam, ethosuximide, levetiracetam, phenobarbital & Gabapentin, lamotrigine, phenytoin, tiagabine, valproate, topiramate \\
\hline Picrotoxin $[78,80]$ & Mice & $\begin{array}{l}\text { Diazepam, carbamazepine, ethosuximide, phenobarbital, } \\
\text { tiagabine, valproate }\end{array}$ & Levetiracetam, gabapentin, lamotrigine, topiramate \\
\hline
\end{tabular}

1 Topiramate showed partial protection in the zebrafish AG model but not in mice.

2 Gabapentin showed activity in mice but not in the zebrafish PTZ test.

${ }^{3}$ Levetiracetam decreased the number of SWDs induced by PTZ.

high-throughput screening of novel lead compounds in the development of therapeutics against treatment-resistant seizures.

Supplementary data to this article can be found online at http://dx. doi.org/10.1016/j.yebeh.2015.03.019.

\section{Acknowledgments}

C. Esguerra was supported by the Industrial Research Fund of the KU Leuven. We thank P. Verstreken for providing access to electrophysiology equipment. We also thank A. Ny for her advice in data handling and E. Gebruers for her assistance in EEG scoring. Finally, we would like to thank F. Coddens and M.C. Tordeur for technical assistance and J. Johnson for excellent zebrafish care.

\section{Disclosure}

This study was partially conducted by UCB Pharma, and KL, CCR, and RMK are employees of UCB, the manufacturer of levetiracetam. All authors confirm that they have read the Journal's position on ethical publication and affirm that this report is consistent with those guidelines.

\section{References}

[1] Löscher W. Animal models of epilepsy for the development of antiepileptogenic and disease-modifying drugs. A comparison of the pharmacology of kindling and poststatus epilepticus models of temporal lobe epilepsy. Epilepsy Res 2002;50:105-23.

[2] Remy S, Beck H. Molecular and cellular mechanisms of pharmacoresistance in epilepsy. Brain 2006;129:18-35.

[3] Kwan P, Schachter SC, Brodie MJ. Drug-resistant epilepsy. N Engl J Med 2011;365: 919-26.

[4] Kwan P, Arzimanoglou A, Berg AT, Brodie MJ, Allen Hauser W, Mathern G, et al. Definition of drug resistant epilepsy: consensus proposal by the ad hoc Task Force of the ILAE Commission on Therapeutic Strategies. Epilepsia 2010;51:1069-77.

[5] Simonato M, Löscher W, Cole AJ, Dudek FE, Engel J, Kaminski RM, et al. Finding a better drug for epilepsy: preclinical screening strategies and experimental trial design. Epilepsia 2012;53:1860-7.

[6] Galanopoulou AS, Buckmaster PS, Staley KJ, Moshé SL, Perucca E, Engel J, et al. NIH public access. Epilepsia 2012;53:571-82.

[7] Schmidt D, Löscher W. Drug resistance in epilepsy: putative neurobiologic and clinical mechanisms. Epilepsia 2005;46:858-77.

[8] Kovács R, Heinemann U. Models in research of pharmacoresistant epilepsy: present and future in development of antiepileptic drugs. Curr Med Chem 2014;21:689-703.

[9] Volk HA, Löscher W. Multidrug resistance in epilepsy: rats with drug-resistant seizures exhibit enhanced brain expression of P-glycoprotein compared with rats with drug-responsive seizures. Brain 2005;128:1358-68.

[10] Ebert U, Löscher W. Characterization of phenytoin-resistant kindled rats, a new model of drug-resistant partial epilepsy: influence of genetic factors. Epilepsy Res 1999;33:217-26.

[11] Srivastava AK, White HS. Carbamazepine, but not valproate, displays pharmacoresistance in lamotrigine-resistant amygdala kindled rats. Epilepsy Res 2013;104:26-34.

[12] Champagne DL, Hoefnagels CCM, de Kloet RE, Richardson MK. Translating rodent behavioral repertoire to zebrafish (Danio rerio): relevance for stress research. Behav Brain Res 2010;214:332-42.

[13] Baraban SC, Taylor MR, Castro PA, Baier H. Pentylenetetrazole induced changes in zebrafish behavior, neural activity and c-fos expression. Neuroscience 2005;131: 759-68.

[14] Baraban SC, Dinday MT, Castro PA, Chege S, Guyenet S, Taylor MR. A large-scale mutagenesis screen to identify seizure-resistant zebrafish. Epilepsia 2007;48:1151-7.
[15] Afrikanova T, Serruys A-S K, Buenafe OEM, Clinckers R, Smolders I, de Witte PA, et al Validation of the zebrafish pentylenetetrazol seizure model: locomotor versus electrographic responses to antiepileptic drugs. PLoS One 2013;8:e54166.

[16] Hortopan GA, Dinday MT, Baraban SC. Zebrafish as a model for studying genetic aspects of epilepsy. Dis Model Mech 2010;3:144-8.

[17] Ramirez IB-R, Pietka G, Jones DR, Divecha N, Alia A, Baraban SC, et al. Impaired neural development in a zebrafish model for Lowe syndrome. Hum Mol Genet 2012;21: 1744-59.

[18] Chege SW, Hortopan GA, T Dinday M, Baraban SC. Expression and function of KCNQ channels in larval zebrafish. Dev Neurobiol 2012;72:186-98.

[19] Mahmood F, Mozere M, Zdebik AA, Stanescu HC, Tobin J, Beales PL, et al. Generation and validation of a zebrafish model of EAST (epilepsy, ataxia, sensorineural deafness and tubulopathy) syndrome. Dis Model Mech 2013;6:652-60.

[20] Baraban S, Dinday M, Hortopan G. Drug screening in Scn1a zebrafish mutant identifies clemizole as a potential Dravet syndrome treatment. Nat Commun 2013;4: 2410.

[21] Suls A, Jaehn JA, Kecskés A, Weber Y, Weckhuysen S, Craiu DC, et al. De novo loss-offunction mutations in $\mathrm{CHD} 2$ cause a fever-sensitive myoclonic epileptic encephalopathy sharing features with Dravet syndrome. Am J Hum Genet 2013;93:967-75.

[22] Baxendale S, Holdsworth CJ, Santoscoy PM, Harrison MRM, Fox J, Parkin CA, et al. Identification of compounds with novel anti-convulsant properties in a zebrafish model of epileptic seizures. Dis Model Mech 2012;5:773-84.

[23] Mandhane SN, Aavula K, Rajamannar T. Timed pentylenetetrazol infusion test: a comparative analysis with s.c.PTZ and MES models of anticonvulsant screening in mice. Seizure 2007; 16:636-44.

[24] Loscher W. Valproate: a reappraisal of its pharmacodynamic properties and mechanisms of action. Prog Neurobiol 1999;58:31-59.

[25] Ben-Menachem E. Mechanism of action of vigabatrin: correcting misperceptions. Acta Neurol Scand Suppl 2011;124:5-15.

[26] Moldrich RX, Chapman AG, De Sarro G, Meldrum BS. Glutamate metabotropic receptors as targets for drug therapy in epilepsy. Eur J Pharmacol 2003;476:3-16.

[27] Dingledine R. Glutamatergic mechanisms related to epilepsy: ionotropic receptors. In: Noebels JL, Avoli M, Rogawski MA, Olsen RW, Delgado-Escueta AV, editors. Jasper's basic mechanisms of the epilepsies. 4th ed. Bethesda (MD): National Center for Biotechnology Information (US); 2012, p. 122-31.

[28] Meldrum B. The role of glutamate in epilepsy and other CNS disorders. Neurology 1994;44(Suppl. 8):14-23.

[29] Meurs A, Clinckers R, Ebinger G, Michotte Y, Smolders I. Seizure activity and changes in hippocampal extracellular glutamate, GABA, dopamine and serotonin. Epilepsy Res 2008;78:50-9.

[30] Mehta A, Prabhakar M, Kumar P, Deshmukh R, Sharma PL. Excitotoxicity: bridge to various triggers in neurodegenerative disorders. Eur J Pharmacol 2013:698:6-18.

[31] Gryder DS, Rogawski MA. Selective antagonism of GluR5 kainate-receptor-mediated synaptic currents by topiramate in rat basolateral amygdala neurons. J Neurosci 2003;23:7069-74.

[32] Rogawski MA. AMPA receptors as a molecular target in epilepsy therapy. Acta Neurol Scand Suppl 2013;127:9-18.

[33] Scheyer RD. Involvement of glutamate in human epileptic activities. Prog Brain Res 1998;116:359-69.

[34] Treiman DM. GABAergic mechanisms in epilepsy. Epilepsia 2001;42(Suppl. 3):8-12.

[35] Mody I. Another "tonic" in the realm of epilepsy. Epilepsy Curr 2004;4:248-9.

[36] Lloyd K, Bossi L, Morselli P. Alterations of GABA-mediated synaptic transmission in human epilepsy. Adv Neurol 1986;44:1033-44.

[37] Horton RW. The role of 2-keto-4-pentenoic acid in seizures induced by allylglycine. Biochem Pharmacol 1978;27:1471-7.

[38] Taberner P, Keen P. Brain and blood levels of allylglycine in mice following doses sufficient to inhibit glutamate decarboxylase. J Neurochem 1977;29:595-7.

[39] Chapman AG. Regional changes in transmitter amino acids during focal and generalized seizures in rats. J Neural Transm 1985;63:95-107.

[40] Fisher SK, Davies WE. The effect of the convulsant allylglycine (2-amino-4-pentenoic acid) on the activity of glutamic acid decarboxylase and the concentration of GABA in different regions of guinea pig brain. Biochem Pharmacol 1976;25:1881-5.

[41] Horton RW, Meldrum BS. Seizures induced by allylglycine, 3-mercaptopropionic acid and 4-deoxypyridoxine in mice and photosensitive baboons, and different modes of inhibition of cerebral glutamic acid decarboxylase. Br J Pharmacol 1973; 49:52-63.

[42] Roper S. Inhibition of Mauthner cells by allylglycine. Nature 1970;226:373-4.

[43] Meldrum BS, Chapman AG, Horton RW. Clobazam: anticonvulsant action in animal models of epilepsy [proceedings]. Br J Clin Pharmacol 1979;7(Suppl. 1):59-60. 
[44] Nakamura J, Mine K, Yamada S. Effects of anticonvulsants on the electroconvulsive threshold lowered by DA, 5-HT or GABA depletion. Kurume Med J 1989;37: 253-9.

[45] Ashton D, Wauquier A. Effects of some anti-epileptic, neuroleptic and gabaminergic drugs on convulsions induced by D,L-allylglycine. Pharmacol Biochem Behav 1979; 11:221-6.

[46] Drago F, Valerio C, Clementi G, Scapagnini U. Effects of flunarizine on experimentallyinduced convulsions in animals. Funct Neurol 1986;1:529-32.

[47] Sebe J, Baraban S. The promise of an interneuron-based cell therapy for epilepsy. Dev Neurobiol 2011;71:107-17.

[48] Marx M, Haas CA, Häussler U. Differential vulnerability of interneurons in the epileptic hippocampus. Front Cell Neurosci 2013;7:167.

[49] Kitamura K, Yanazawa M, Sugiyama N, Miura H, Iizuka-Kogo A, Kusaka M, et al. Mutation of ARX causes abnormal development of forebrain and testes in mice and X-linked lissencephaly with abnormal genitalia in humans. Nat Genet 2002; 32:359-69.

[50] Kato M, Dobyns WB. X-linked lissencephaly with abnormal genitalia as a tangentia migration disorder causing intractable epilepsy: proposal for a new term, "interneuronopathy". J Child Neurol 2005;20:392-7.

[51] Friocourt G, Parnavelas JG. Mutations in ARX result in several defects involving GABAergic neurons. Front Cell Neurosci 2010;4:4.

[52] Jones DL, Howard MA, Stanco A, Rubenstein JLR, Baraban SC. Deletion of Dlx1 results in reduced glutamatergic input to hippocampal interneurons. J Neurophysiol 2011; 105:1984-91.

[53] Powell EM, Campbell DB, Stanwood GD, Davis C, Noebels JL, Levitt P. Genetic disruption of cortical interneuron development causes region- and GABA cell type-specific deficits, epilepsy, and behavioral dysfunction. J Neurosci 2003;23:622-31.

[54] Eagleson KL, Bonnin A, Levitt P. Region- and age-specific deficits in gammaaminobutyric acidergic neuron development in the telencephalon of the uPAR $(-1-)$ mouse. J Comp Neurol 2005;489:449-66.

[55] Valdés-Sánchez L, Escámez T, Echevarria D, Ballesta JJ, Tabarés-Seisdedos R, Reiner $\mathrm{O}$, et al. Postnatal alterations of the inhibitory synaptic responses recorded from cortical pyramidal neurons in the Lis1/sLis1 mutant mouse. Mol Cell Neurosci 2007;35 220-9.

[56] Jones DL, Baraban SC. Characterization of inhibitory circuits in the malformed hippocampus of Lis1 mutant mice. J Neurophysiol 2007:98:2737-46.

[57] Kawabata I, Kashiwagi Y, Obashi K, Ohkura M, Nakai J, Wynshaw-Boris A, et al. LIS1dependent retrograde translocation of excitatory synapses in developing interneuron dendrites. Nat Commun 2012;3:722.

[58] Jones DL, Baraban SC. Inhibitory inputs to hippocampal interneurons are reorganized in Lis1 mutant mice. J Neurophysiol 2009;102:648-58.

[59] Barton ME, Klein BD, Wolf HH, White HS. Pharmacological characterization of the $6 \mathrm{~Hz}$ psychomotor seizure model of partial epilepsy. Epilepsy Res 2001:47:217-27.

[60] Racine R. Modification of seizure activity by electrical stimulation: II. Motor seizure. Electroencephalogr Clin Neurophysiol 1972;32:281-94.

[61] Schauwecker PE. Seizure-induced neuronal death is associated with induction of cJun N-terminal kinase and is dependent on genetic background. Brain Res 2000;884: 116-28.

[62] Hortopan GA, Dinday MT, Baraban SC. Spontaneous seizures and altered gene expression in GABA signaling pathways in a mind bomb mutant zebrafish. J Neurosci 2010;30:13718-28.

[63] Van Hemelrijck A, Sarre S, Smolders I, Michotte Y. Determination of amino acids associated with cerebral ischaemia in rat brain microdialysates using narrowbore liquid chromatography and fluorescence detection. J Neurosci Methods 2005;144: 63-71.
[64] Alberici M, Rodriguez de Lores Arna, De Robertis E. Glutamic acid decarboxylase inhibition and ultrastructural changes by the convulsant drug allylglycine. Biochem Pharmacol 1969;18:137-43.

[65] Barnwell LFS, Lugo JN, Lee WL, Willis SE, Gertz SJ, Hrachovy RA, et al. Kv4.2 knockout mice demonstrate increased susceptibility to convulsant stimulation. Epilepsia 2009;50:1741-51.

[66] Pena F, Tapia R. Seizures and neurodegeneration induced by 4-aminopyridine in rat hippocampus in vivo: role of glutamate- and GABA-mediated neurotransmission and of ion channels. Neuroscience 2000;101:547-61.

[67] Tutka P, Mróz T, Klucha K, Piekarczyk M, Wielosz M. Bupropion-induced convulsions: preclinical evaluation of antiepileptic drugs. Epilepsy Res 2005;64:13-22.

[68] Wilcox KS, Dixon-Salazar T, Sills GJ, Ben-Menachem E, White HS, Porter RJ, et al. Issues related to developments of new antiseizure treatments. Epilepsia 2013;54:24-34.

[69] Buenafe OE, Orellana-Paucar A, Maes J, Huang H, Ying X, De Borggraeve W, et al. Tanshinone IIA exhibits anticonvulsant activity in zebrafish and mouse seizure models. ACS Chem Neurosci 2013;4:1479-87.

[70] Horton R, Meldrum B. A comparison of the effects of allylglycine and 2-keto-4pentenoic acid on cerebral glutamic acid decarboxylase activity and convulsions in mice. Br J Pharmacol 1977;3:477P.

[71] Faiman M, Haya K, Zempel J, Schowen R. GABA metabolism in $\mathrm{O}_{2}$-induced convulsions. Brain Res Bull 1980;5:789-92.

[72] Lima TT, Begnini J, de Bastiani J, Fialho DB, Jurach A, Ribeiro MC, et al. Pharmacological evidence for GABAergic and glutamatergic involvement in the convulsant and behavioral effects of glutaric acid. Brain Res 1998;802:55-60.

[73] Esclapez M, Houser C. Up-regulation of GAD65 and GAD67 in remaining hippocampal GABA neurons in a model of temporal lobe epilepsy. J Comp Neurol 1999;412: 488-505.

[74] Vianello M, Tavolato B, Giometto B. Glutamic acid decarboxylase autoantibodies and neurological disorders. Neurol Sci 2002;23:145-51.

[75] Gale K. Role of GABA in the genesis of chemoconvulsant seizures. Toxicol Lett 1992: 64-5 [Spec: 417-28]

[76] Naylor DE. Glutamate and GABA in the balance: convergent pathways sustain seizures during status epilepticus. Epilepsia 2010;51(Suppl. 3):106-9.

[77] Watanabe Y, Takechi K, Fujiwara A, Kamei C. Effects of antiepileptics on behavioral and electroencephalographic seizure induced by pentetrazol in mice. J Pharmacol Sci 2010;112:282-9.

[78] Holmes G, Zhao Q. Choosing the correct AED: from animal studies to the clinic. Pediatr Neurol 2008;38:151-62.

[79] Auta J, Impagnatiello F, Kadriu B, Guidotti A, Costa E. Imidazenil: a low efficacy agonist at alpha1 - but high efficacy at alpha5-GABAA receptors fail to show anticonvulsant cross tolerance to diazepam or zolpidem. Neuropharmacology 2008;55: 148-53.

[80] Turski L, Stephens D, Jensen L, Petersen E, Meldrum B, Patel S, et al. Anticonvulsant action of the beta-carboline abecarnil: studies in rodents and baboon, Papio papio. J Pharmacol Exp Ther 1990;253:344-52.

[81] Johnson P, Lowry C, Truitt W, Shekhar A. Disruption of GABAergic tone in the dorsomedial hypothalamus attenuates responses in a subset of serotonergic neurons in the dorsal raphe nucleus following lactate-induced panic. J Psychopharmacol 2008;22:642-52.

[82] Johnson PL, Samuels BC, Fitz SD, Federici LM, Hammes N, Early MC, et al. Orexin 1 receptors are a novel target to modulate panic responses and the panic brain network. Physiol Behav 2012;107:733-42.

[83] Handley SL, Singh L. Modulation of 5-hydroxytryptamine-induced head-twitch response by drugs acting at GABA and related receptors. Br J Pharmacol 1985;86: 297-303. 